\title{
2020 Buildings Young Investigator Award: Announcement and Interview with the Winner
}

\author{
Buildings Editorial Office
}

check for updates

Citation: Office, B.E. 2020 Buildings Young Investigator Award: Announcement and Interview with the Winner. Buildings 2021, 11, 39. https://doi.org/10.3390/ buildings 11020039

Received: 21 January 2021

Accepted: 23 January 2021

Published: 25 January 2021

Publisher's Note: MDPI stays neutral with regard to jurisdictional claims in published maps and institutional affiliations.

Copyright: (C) 2021 by the author. Licensee MDPI, Basel, Switzerland. This article is an open access article distributed under the terms and conditions of the Creative Commons Attribution (CC BY) license (https:/ / creativecommons.org/licenses/by/ $4.0 /)$.
MDPI AG, St. Alban-Anlage 66, 4052 Basel, Switzerland; Buildings@mdpi.com

After an extensive voting period, we are proud to present the winner of the Buildings Young Investigator Award:

Chiara Bedon (born 1983) is Assistant Professor at the University of Trieste (Italy) in the Department of Engineering and Architecture, where she has taught "Structural Analysis" since 2012. At the same University, she received her BSc (2003) and MSc (2007) degrees in Civil Engineering, a 2nd level Master course degree (2008, $400 \mathrm{~h}$ ) on the design of earthquake-resistant buildings and her Ph.D. degree in 2012. She started as a junior Assistant Professor, and is now a senior (tenure track) Assistant Professor at the same department. Dr. Bedon received the National Scientific Qualification (ASN) from the Italian Ministry of Education, Research and Instruction to act as Associate (since 2017) and Full (since 2020) Professor for the Structural Engineering/Building Technology sector (08/B3-Tecnica delle costruzioni).

So far, Dr. Bedon has collaborated with several national and international partners, including Universities and industrial companies that operate in the building field. Since 2012, she has been involved in several international research projects and networks, like the EU Joint Research Centre (JRC), several EU-COST networks as a national delegate or working group member, three NATO "Science for Peace and Security" advanced training courses/workshops and more.

As an advisor or supervisor for several BSc and MSc (35) and PhD students (4), Dr. Bedon acts as an invited lecturer for professional courses or international scientific conferences and committees. Over the years, she has been the recipient of several grants for international mobility, best paper awards, editorial prizes and more. She is listed in the 2020 worldwide database of "Top 2\% Scientists" (top 0.27\% in the "Building and Construction" section) for the impact and excellence of her research (Stanford University-PLOS Biology). Dr. Bedon has published 152 Scopus-indexed documents, including articles, book chapters, reviews and conference papers (h-index $=23$ ). She is also the co-author for several technical documents in support of structural analysis and design.

\section{Could You Give Us a Brief Introduction of Yourself to the Readers?}

Hello, my name is Chiara Bedon and I am Assistant Professor at the University of Trieste (Italy), Department of Engineering and Architecture.

\section{What's Your Current Research and Why Did You Choose This Research Field?}

My research activity deals with the analytical, numerical and experimental analysis of constructional materials, components and systems in the building sector. Since my PhD research activities, I started to work especially with glass for structures.

Most of my past and current research is in fact focused on the formulation of design methods of practical use for the verification of structural members composed of glass or timber, or composite solutions. My interest and background is especially for extreme loading conditions (like explosions, earthquakes, fire, impact) that require even more attention and dedicated calculation tools in support of design. In this specific framework I'm working at the impact performance (and possible mitigation) of glass facades. Due to the typical brittleness of glass, their vulnerability is even more pronounced than "traditional" 
constructional materials. Thus the direct effect of enhanced design procedures reflects on improved structural behavior (with optimized materials, members, etc.) but especially in higher safety levels for the occupants.

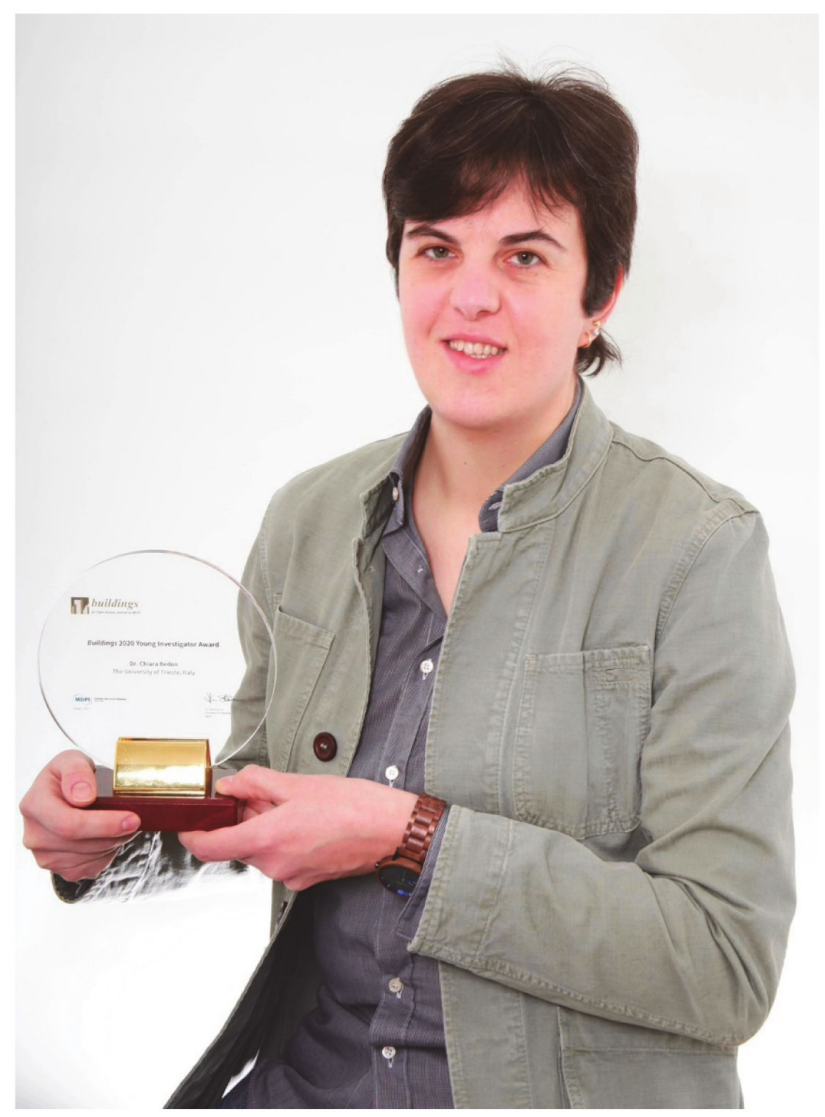

\section{Which Research Topics Do You Think Are of Particular Interest to the Research Community in the Coming Years?}

Glass in buildings is still rather new, compared to other traditional materials for constructions (concrete, steel), and thus it for sure needs further efforts for different applications. I mean that even simple design configurations can be challenging when you apply new materials or structural concepts. So you can imagine what happens under extreme accidental events.

I think that especially in the next years we will see even further massive use of "transparent building components" in the construction sector. I see this as a direct result of the worldwide Covid-19 pandemic that changed all the day-life rules, and the consequent actual need to elaborate new design concepts/space management for private buildings, public offices, open places, infrastructures.

\section{Have You Ever Encountered any Difficulties When You Conduct Research? How Did You Overcome Them?}

Sure, I did encounter technical difficulties, but this is part of the ongoing challenge of my activity. In the research field, especially when you move your first steps, it's not simple and trivial to find breakout results. You could have innovative ideas but wrong methods, or good approaches but no budget, etc. Hard working can be thus even more challenging and frustrating in this case. Further, what I see in some early stage scientists is the lack of an honest interest for science. Additional difficulties may derive from economical issues and possible unavailability of research funding. I suffered for this in my first steps, but worked hard in any case. And now it seems that the approach was successful. If you want, you can always find the best way to go on. This is why in \#5 I talk about patience, 
perseverance and tenacity. My final suggestion is bite the bullet and positive results will arrive. As a last note, major issues of these last months for sure come from the remote working rules and the rigid restrictions due to the ongoing sanitary emergency.

\section{What Qualities Do You Think Young Scientists Need?}

Looking back at my past, I can for sure say that endless curiosity and passion are fundamentals. They continuously move you towards new challenges, one after the other. Nothing else will push you like them.

But especially in the early stage, career is not always simple to overcome the planned targets, and thus a big bag of patience, perseverance and tenacity is very important.

Finally, being a good listener can be certainly helpful to find dialogue, collaboration and networking with the community. Open your mind, experience new research groups and labs, never stop travelling. The well-known axiom "never stop growing and learning" is a must. And who I am now comes also from the above concepts.

\section{Buildings is an Open Access Journal. How Do You Think Open Access Impacts the Authors?}

Open Access (OA) scientific journals are of great support for scientists, in general. OA papers have a direct impact on the scientific community, but can be also shared with other stakeholders, and this further maximizes the research efforts. The basic issue, however, is that OA publications need special fees, and most of the early stage researchers are not able to afford this.

I appreciate very much publishers like MDPI, due to the continuous initiatives that offer to provide financial support to young scientists (travel awards, young investigator awards, etc.) or also waive the standard fees with reviewer activity/editorial activity recognition. For sure, this Award gives me new energy for next challenges, thus I want to acknowledge again MDPI, the Editor-in-Chief for Buildings and all the evaluation committee that was involved in the selection. But I also want to spend few words for all the colleagues that I had/I have the opportunity to join on several research challenges. 